To simply base fees on time would seem

to me to be a tremendous loss in potential

earning if the patient values dentistry.

\section{Not at any price}

In the past general dental practitioners have tended to combine running a business with providing a dental service for the community, a tricky blend of skills and expertise. Since the inception of the NHS this mix of commercial and clinical has been relatively successful, especially in the early days when the NHS paid the bulk of patient costs; fee setting was unnecessary for most practitioners because the system imposed the fees and patients knew little about the true cost of dental care. Slowly the emphasis on who was paying for dentistry shifted, until most fee-paying patients were contributing substantially to their treatment, but the actual fees were still set by the NHS. All that may change in the future, and as a result, awareness of fee-setting is becoming more important.

Thus it was extremely interesting to see the paper in this issue of the $B D J$ on factors affecting fee setting for private treatment in general dental practice. The paper describes some research carried out on dentists who are members of the British Society for General Dental Surgery, and the response rate of $78 \%$ is encouraging. In essence the questionnaire asked these dentists, most of whom are totally or predominantly private, whether they sought advice in fee-setting, what method they used, how they calculated the fees, whether specialist status had any effect on fees, and the effect of the proportion of private treatment provided. The results are not only fascinating, but demonstrate quite clearly the lack of business acumen that still resides within many dental practitioners (although whether that is a good thing or not is a moot point). It would appear, from the 142 replies, that the predominant factor dentists use in determining fee setting is clinical time. Other factors such as laboratory fees, profit, practice overheads and factors such as the difficulty in treating particular patients are much less relevant. In other words, the majority of dentists base their fees on the time required.

In most businesses fee setting is referred to as 'pricing': a complex subject that can be viewed in a number of ways. For many people pricing is not as simple as charging for time. Price is an amount that is fair for both customer and seller, and is based on perceived value. We all know this to be true, especially if we take a walk down any high street and look in shop windows. The cost of a haircut for me can vary from $£ 5$ - $£ 35$ depending on where I go and whom I choose. The cost of a train ticket can vary even more depending on a number of complex, inexplicable rules I have never worked out, and in each case the journey is the same. The cost of an optical check and a pair of glasses (with or without a free extra pair) also differs, not just from shop to shop but in the same shop. In all these cases time spent is probably the least relevant factor.

Price depends on perceived value. Different people value a haircut, a first class ticket, an eye examination and a pair of glasses, in different ways. We are happy to pay more when we value what we are buying, and the only way we can appreciate the value is when we understand the benefits. All of this is an important part of selling, still a somewhat taboo subject in healthcare (but we are getting better at accepting it). So, for some patients, a price estimated purely on clinical time may be too low, while for others it would be too high. It depends on the value we put on what we are buying, and that requires more than a simple explanation. So to simply base fees on time would seem to me to be a tremendous loss in potential earning if the patient values the dentistry.

Perhaps this lack of appreciation of how to set prices is one reason why most of the dentists responding to the research questions in the paper tend to seek advice from colleagues as a first option. Even more surprising is the admission that only nine out of 102 replies ask a financial consultant for help in setting prices, and only seven use the BDA/GDPA fee guide.

All of this emphasises the one point that was only touched upon in the paper - the patient's value of dentistry as a factor in setting prices. Of course most dentists are unaware of what each patient values, something that would have been thoroughly researched in many other businesses. Yet how much patients really value dentistry is a goldmine that is still largely untapped in dental practice. Now that is definitely good news.

Mike Grace, Editor

m.grace@bda.org

doi: $10.1038 / s j . b d j .4811563$ 